\title{
Educational Press for Remote Experimentation Applied in the Spring to Study Hooke's Law
}

\author{
Luan Carlos da Silva Casagranrde ${ }^{1}$, Vilson Gruber ${ }^{1}$, Roberval Marcelino ${ }^{1}$, Yuri Crotti ${ }^{1}$, Lucas Boeira Michels ${ }^{2}$ \\ and Lirio Schaeffer ${ }^{3}$ \\ 1 Universidade Federal de Santa Catarina, Jardim das Avenidas, Araranguá 88900, Brazil \\ 2 Instituto Federal de Santa Catarina, Cidade Alta , Araranguá 88905, Brazil \\ 3 Universidade Federal do Rio Grande do Sul, Farroupilha, Porto Alegre 91501, Brazil
}

\begin{abstract}
The aim of this study is to report the use of RE (remote experimentation) in an educational press. The authors developed this remote experiment with the objective to study the Hooke's law through the analysis of the coil spring. The remote experiment is available in a website, where the students can manipulate and observe the educational press and confirm Hooke's statements with the output information. In addition, the students will have the opportunity to read in the website about the educational press, the physical law, and the use of the press in industrial processes. This remote experimentation exerts a force in the mechanical spring creating a deformation. In the defined point, the microcomputer will collect the data from the sensors, and it will save this data in the database. After the process execution, a graph with the data will be plotted in the website. The tests confirm that the educational press has informational potential because it returned values consistent with Hooke's law and the experiment presented repetition in all tests realized.
\end{abstract}

Key words: Educational press, Hooke’s law, physical law, industrial process, remote experimentation.

\section{Introduction}

The difficulties in teaching and understanding certain concepts usually occur by lack of practice and interaction. This interaction with reality can be demonstrated through experiments, which have the ability to prove or disprove an event or demonstrate the cause and effect of the theory.

However, the experiments have numerous restrictions, such as cost of the experiment, space limitation, security problems, and maintenance [1].

Advances in information and communication technology are offering new opportunities to reduce these restrictions [1, 2]. For example, the possibility of forming a remote experiment network is a considerable way to contain the issues that are disabling some schools around the world to offer

Corresponding author: Luan Carlos da Silva Casagrande, engineering undergraduate student, research fields: remote experimentation, embedded systems. E-mail: luanccasagrande@gmail.com. hands-on activities for their students.

This paper presents the development of a remote laboratory and educational press that were designed to teach Hooke's Law. In addition, this work argues that the press is a viable educational experiment that can help in high school and undergraduate classes.

Moreover, it will demonstrate a different structure for remote experimentation aiming to reduce the final cost and the difficulty of developing an experiment.

\section{Remote Experiments}

Experimentation develops the capabilities of comprehension, simplification, and modulation of a problem, formulation of a hypothesis, methodological preposition, and data analysis, among other skills [3]. This means that experimentation is an important factor in the educational process, and because of the difficulties to maintain a laboratory, remote laboratories are gaining importance.

The integration of telecommunication technologies 
and computer science with virtual instrumentation enabled the development of remote laboratories accessed via the Internet in real time, ensuring a richer collaborative experience for the student. In addition, this is a good way for schools to solve the problem of lack of hands-on activity [4].

Observing this fact, some laboratories around the world are constantly developing new experiments with the objective to contribute to the teaching process.

\section{Educational Press}

The mechanical press is a machine that is commonly used in industries and in machine shops in general. There are many kinds of presses, but most are used for shaping and cutting.

The educational press has a reduced physical size, but it was developed following all the industrial characteristics. It is a conformation mechanical press, and in this remote experiment, the press will compress a coil spring.

The main objective of this machine for this experiment is to use the output data to calculate the spring constant through Hooke's law and to prove that this value is really constant during the experimentation process. Physics and Mechanics are covered with this experiment, and consequently, this remote experiment can be utilized in high school or undergraduate classes.

\section{Raspberry Pi}

Raspberry $\mathrm{Pi}$ is a microcomputer that was developed by the Raspberry Pi Company aiming to develop the learning process in Computer Science courses. Nowadays, this microcomputer is one of the most affordable microcomputers accessible in the market. In addition, this microcomputer can provide a structure model for a remote experiment on only one board. Consequently, both the level of difficulty and the final cost to develop the experiment will be lower. The Raspberry Pi has $700 \mathrm{MHz}$ of processor, $512 \mathrm{MB}$ of RAM, HDMI and RCA video output, audio output, SD card input, RJ14 input, two USB inputs, and the GPIO (general purpose input/output) [5]. All these resources can offer new alternatives for the remote experimentation. The average remote experimentation structure consists of a server, the process, and Cams [6]. Nevertheless, the Raspberry Pi which could alone run the web server is the main interface to the World Wide Web. In addition, the Raspberry $\mathrm{Pi}$ has the camera and can stream live video to show the experiment to the user [7]. These solutions indicate that the Raspberry $\mathrm{Pi}$ could replace the server computer that is in charge of the interface with the users and the IP-Cam that is utilized for the streaming of live video. Furthermore, the Raspberry Pi has the General Purpose Input Output, a connection between the microcomputer and the general-purpose electronics. This resource gives the Raspberry Pi resources of data acquisition, instrumentation and control systems [8]. Therefore, the Raspberry Pi could substitute the microcontroller that is responsible for controlling the machine. In the educational press, the Raspberry Pi is responsible for the interface between the user and the machine through the web-server, to control the machine through the general purpose input-output, and for monitoring the press with two webcams controlling the video streaming.

Besides these three resources needed for the experiment, the Raspberry $\mathrm{Pi}$ has the capacity to realize a huge number of tasks, and consequently, this microcomputer can be the solution for some experiments.

\section{Experimentation Process and Expected Results}

The experiment consists of two distinct areas that work together, as exemplified in Fig. 1. The user will communicate with a friendly interface, and the controlling process will not be visible for the user.

The experimentation process will initiate with the connection with the website (www.labtel.com.br). The 


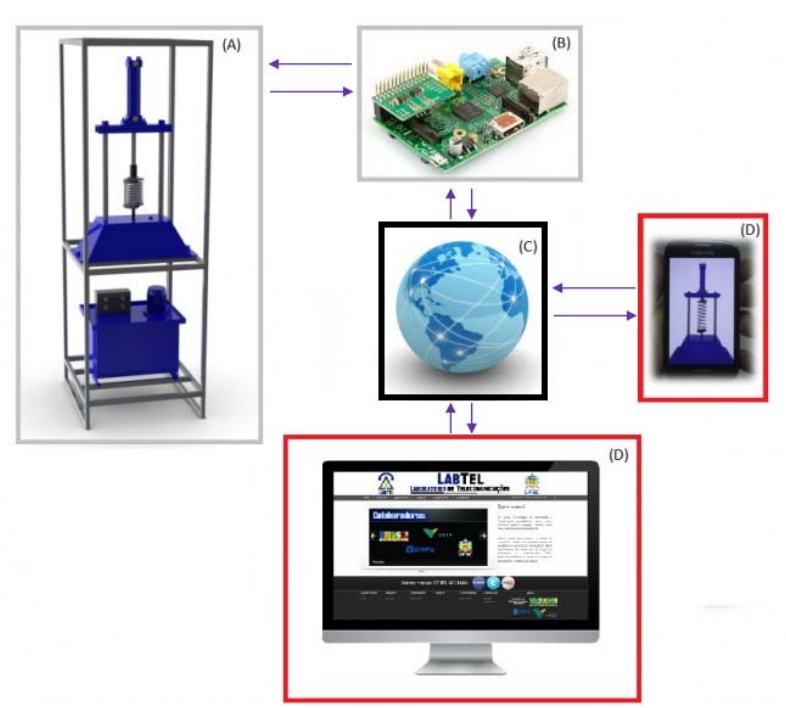

Fig. 1 Composition of remote experiment.

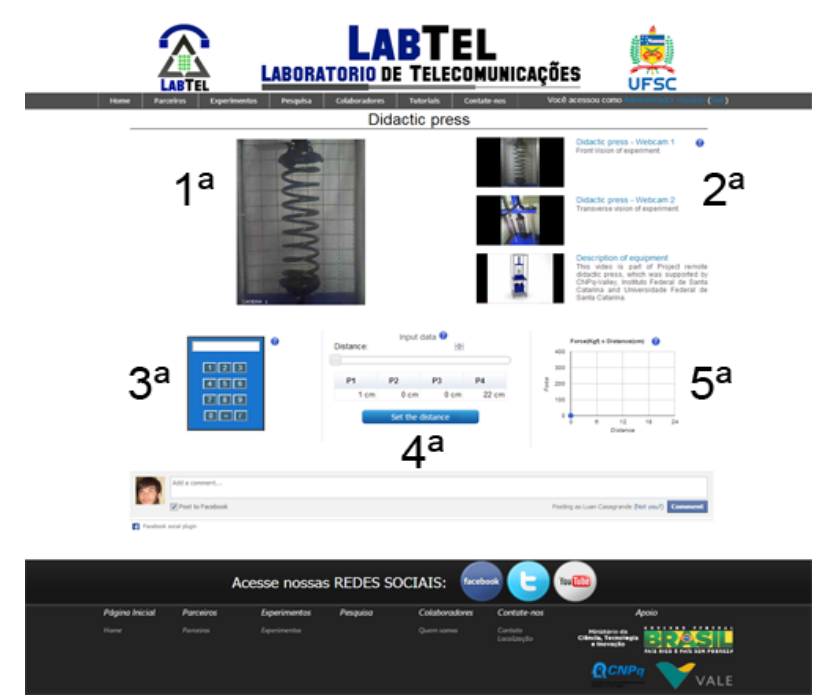

Fig. 2 Human-machine interface.

management and access for the remote experiment is done by the Moodle-LMS (learning management system).

After the educational press, the user will access the experiment support materials page. In this page, the user will be able to study about the Hooke's law, the educational press, and the press in the industry. A teacher with the necessary knowledge in this area will be responsible to provide this content.

In the experimentation page, the webpage will show some information and will offer the opportunity to define the position of the webcam for the student. Each part of the experimentation page has a question mark, where the students can solve their problems about the experimentation process.

The main five areas in the experiment website are being shown in the Fig. 2. Each part has its own importance in the experimentation process.

The first is the area where the students will watch the educational press live. This area will change with the user settings because the website will offer the opportunity to choose among front sight, transversal vision and explanatory videos. The settings will be defined in the area 2.

The transversal vision of the experiment is important in this process because the students will be able to prove that this experiment is a real experiment and to see the mechanical structure of the educational press.

In the fourth area, the users will need to define the deformations points in the table of deformations. In this table, two of four points have already been defined. The other points the user will define through the slide bar. The first deformation point always will be defined as $1 \mathrm{~cm}$ and the least as maximum deformation, $22 \mathrm{~cm}$. With the four points, the experiment will be ready to start.

The output data will be shown in the fifth area. In this space, a graph will be plotted after the experimentation process. This graph will present a connection between the applied force and the spring size variation. The students will be able to calculate the spring constant and to prove that this value is constant during all the process through the data in the graph.

The third area will present a calculator to help the students after the experimentation process. The main objective is to calculate the spring constant through the Hooke's law.

After the user begin the experimentation process, the machine process will begin in background. A file will be executed in the web-server, and this file will execute the python file responsible for the control of the educational press, data acquisition, and access to 
the database.

After the experimentation process, a file will access again the database and will get the data. A graph will be plotted with this data, and the student will be able to use this data through the dynamic graph.

\section{Data Analyze}

Different simulations were made with the remote experiment with the objective to analyze the precision of the experiment. After 42 different simulations, it was possibly to define that the experiment has the necessaries characteristics to prove the Hooke's law.

With the result, the experiment showed repeatability in all tests. In addition, with 42 trials, it was obtained 168 data from the force applied in the spring, and with this data, it was possible to calculate the constant in each test point. The average value of the spring constant was $14.44 \mathrm{~N} / \mathrm{cm}$ with a standard deviation of $0.35 \mathrm{~N} / \mathrm{cm}$. It is important to describe that the spring is not an ideal coil spring, and consequently, the perfect proportion is not possible. In addition, it is an educational experiment and the measurements may contain errors. For example, the infrared sensor may be unstable in the measurements.

\section{Conclusion}

The advancements in the technology of information and communication are creating new solutions for the education. For example, a remote experimentation lab is an opportunity to reduce the problem of lack of hands-on activity.

This work demonstrated that the educational press, that is a remote experiment, could help the students in physic and mechanic classes proving the Hooke's law.

Moreover, a different structure for remote experimentation was shown in this work. The structure was changed from the average structure with a microcontroller and a server to the Raspberry Pi. In this different structure, the Raspberry $\mathrm{Pi}$ is in charge of the monitoring, control, and the interface with the user. In addition, this microcomputer is responsible for the control of hydraulic valves, data acquisition from the sensors, lamp and motor through the relays, and interface with the users.

\section{References}

[1] Graven, O. H., and Samuelsen, D. A. H. 2013. "Design of a Programming Lab for Embedded Devices via a Remote Lab Using a Combination of a Raspberry Pi and an Arduino.” In Proceedings of World Conference on E-Learning in Corporate, Government, Healthcare, and Higher Education, 2316-23.

[2] Callaghan, M. J., Harkin, J., McGinnity, T. M., and Maguire, L. P. 2008. "Intelligent User Support in Autonomous Remote Experimentation Environments." Industrial Electronics, IEEE Transactions 55 (6): 2355-67.

[3] Macias, M. E., and Mendez, I. 2007. "E Lab - Remote Electronics Lab in real time." In Proceedings of the Frontiers in Education Conference - Global Engineering: Knowledge Without Borders, Opportunities Without Passports, 10-3.

[4] Ali, M., Vlaskamp, J. H. A., Eddin, N. N., Falconer, B., and Oram, C. 2013. “Technical Development and Socioeconomic Implications of the Raspberry $\mathrm{Pi}$ as a Learning Tool in Developing Countries.” In Proceedings of the Computer Science and Electronic Engineering Conference (CEEC), 103-8.

[5] The Raspberry Pi Fundation. Raspberry Pi (Online). 2013. “Raspberry Pi 1 model B" Raspberry Pi Fundation. Accessed May 20, 2014. Available in internet. URL: https://www.raspberrypi.org/products/model-b/.

[6] Cardoso, D. C, and Takahashi, E. K. 2011. "Remote Experimentation in Formal Education Activities: A Study From Qualis A Journals.” The Brazilian Journal of Research in Education in Science 11: 4.

[7] Ribeiro, M. 2012. "Interface and Web Server Implementation for an Industrial Automation Remote Laboratory.” Thesis, Universidade Tecnica de Lisboa.

[8] Santana, I., Ferre, M., Izaguirre, E., Aracil, R., and Hernandez, L. 2013. "Remote Laboratories for Education and Research Purposes in Automatic Control Systems.” Industrial Informatics, IEEE Transactions 9: 547 -56. 